\title{
Clinical analysis of microbiologically proven fungal keratitis according to prior topical steroid use: a retrospective study in South Korea
}

\author{
Chan-Ho Cho and Sang-Bumm Lee ${ }^{*}$ (D)
}

\begin{abstract}
Background: To compare the clinical characteristics and treatment outcomes of microbiologically proven fungal keratitis between users and non-users of prior topical steroids (PS and NPS, respectively).

Methods: Eighty-three cases with microbiologically proven fungal keratitis between January 2000 and December 2016 were reviewed retrospectively. Diagnosis of fungal keratitis was made through potassium hydroxide smear, culture, PCR, or biopsy. Baseline epidemiology, predisposing factors, clinical characteristics, microbiological profiles, and treatment outcomes were evaluated and compared between the PS and NPS groups. Treatment failure was defined as any case with complications or requiring surgery. The risk factors for treatment failure were evaluated using multivariate logistic regression in the overall cohort.

Results: A total of 30 cases with PS group and 53 cases with NPS group were included. Of these, sixteen fungal isolates were identified in the PS group and 14 isolates in the NPS group. Candida was the most common organism in both groups (6 cases, respectively), while Aspergillus (4 cases) was found only in the PS group ( $p=0.103)$. No significant differences were observed in the mean age, sex, occupational distribution, epithelial defect size, hypopyon, and presenting best-corrected visual acuity (BCVA) between the two groups. Differences were observed between the PS and NPS groups in terms of previous ocular surface disease (OSD) (43.3\% vs. $22.6 \%, p=0.048)$ and deep infiltration (53.3\% vs. $32.1 \%, p=0.057)$. Regarding treatment outcomes, final BCVA $<0.1$ ( $60 \%$ vs. $44.2 \%, p=0.133$ ), the use of voriconazole (topical $10 \%$ vs. $0 \%, p=0.044$; systemic $23.3 \%$ vs. $1.9 \%, p=0.003)$, surgical intervention ( $43.3 \%$ vs. $20.8 \%, p=0.029)$, and treatment failure ( $46.7 \%$ vs. $22.6 \%, p=0.023$ ) were more common in the PS group than in the NPS group. The significant risk factors for treatment failure were hypopyon (odds ratio [OR] 6.01, $p=0.005$ ) and deep infiltration (OR 4.38, $p=0.013$ ).

Conclusions: Previous OSD and deep infiltration were more common in the PS group compared to the NPS group. The PS group also experienced worse disease progression and treatment outcomes. These results highlight the need for paying attention to the use of steroids in clinical practice.
\end{abstract}

Keywords: Fungal ocular infection, Steroids, Ulcerative keratitis

\footnotetext{
* Correspondence: sbummlee@ynu.ac.kr

Department of Ophthalmology, Yeungnam University College of Medicine,

170, Hyunchung-ro, Nam-gu, Daegu 705-717 (42415), South Korea
}

(c) The Author(s). 2019 Open Access This article is distributed under the terms of the Creative Commons Attribution 4.0 International License (http://creativecommons.org/licenses/by/4.0/), which permits unrestricted use, distribution, and reproduction in any medium, provided you give appropriate credit to the original author(s) and the source, provide a link to the Creative Commons license, and indicate if changes were made. The Creative Commons Public Domain Dedication waiver (http://creativecommons.org/publicdomain/zero/1.0/) applies to the data made available in this article, unless otherwise stated. 


\section{Background}

Fungal keratitis is an important cause of ocular morbidity and has been reported to account for about half of all microbial keratitis cases requiring therapeutic penetrating keratoplasty [1]. Fungal keratitis is a challenging disease to diagnose and treat. Moreover, it is often confused with other infectious keratitis as there is usually insufficient clinical and microbiological evidence during its early stages thereby leading to delayed treatment. Treatment outcomes for fungal keratitis have been found to be worse compared to bacterial keratitis [2]. Furthermore, there are few commercialized topical antifungal agents, and most of these agents have poor penetration in the cornea $[3,4]$.

The risk factors for fungal keratitis include ocular trauma, ocular surface disease, contact lens use, topical steroid use, and systemic immunosuppression [5, 6]. Among these, the prior use of topical corticosteroids has been shown to be a clinically important factor because it can exacerbate the infection [7]. The use of topical steroids in the early stages of infectious keratitis makes it difficult to judge clinical progression because the immune-inflammatory response in the corneal stroma is temporarily improved and the immune response of the host is decreased [8].

Regardless, there is limited understanding of the progression and treatment outcomes of fungal keratitis according to prior exposure to topical steroids. Therefore, we conducted a comparative study of patients with microbiologically proven fungal keratitis according to prior topical steroid use at a tertiary referral center in South Korea. The aim of this study was to compare the epidemiology, predisposing factors, clinical characteristics, microbiological profiles, and treatment outcomes in patients with microbiologically proven fungal keratitis according to prior exposure to topical steroids.

\section{Methods}

This study was conducted at the Yeungnam University Hospital, a tertiary referral center in South Korea. We retrospectively reviewed medical records of microbiologically proven fungal keratitis cases between January 2000 and December 2016. The inclusion criteria were clinical evidence of fungal keratitis and clinical response to antifungal treatment plus one of the following: (a) positive fungal culture from a corneal specimen, (b) positive identification of fungal elements on a $10 \%$ potassium hydroxide $(\mathrm{KOH})$ smear, and (c) histopathology showing presence of fungal elements. The exclusion criteria were fungal keratitis with scleral involvement and cases did not receive antifungal therapy. For the purpose of this study, the overall cases were divided into two groups: those with prior topical steroid use before the diagnosis of fungal keratitis as PS group, and those with no prior topical steroid use before diagnosis as NPS group. This study was approved by the Institutional Review Board of the Yeungnam University Hospital (IRB
No. 2018-11-015), Republic of Korea, and complied with the principles outlined in the Declaration of Helsinki.

Baseline epidemiology, predisposing factors, clinical characteristics, microbiological profiles, and treatment outcomes were evaluated and compared between the PS and NPS groups. The epidemiologic characteristics included age, sex, occupation, symptom duration and whether patient was referred from a primary eye clinic. The symptom duration was defined as the interval from the onset of symptoms to the time of initial presentation. The predisposing factors included previous ocular surface disease (OSD), previous ocular surgery, underlying systemic disease, corneal trauma, and use of contact lens. The initial clinical characteristics included the location, size of the corneal lesion, depth of infiltration, the presence of the hypopyon, and presenting best-corrected visual acuity (BCVA) as determined using the Snellen test. The corneal lesions were divided into central or peripheral lesions based on the half radius of the cornea. The size of corneal lesions was calculated based on the size of the corneal epithelial defect [9]. Depth of infiltration was categorized as either superficial (more than 0 to 50\%) or deep (more than 50 to $100 \%$ ).

Before initiation of therapy, corneal scrapings of all cases were obtained using a No. 15 Bard-Parker knife (Aspen Surgical, Caledonia, MI, USA) after application of $0.5 \%$ proparacaine hydrochloride (Alcaine, Alcon, Fort Worth, TX, USA) for anesthesia. Simultaneously, conjunctival swab was performed for all cases using a sterile cotton-tipped swab for thioglycolate broth. Scrapings were smeared on glass slides and Gram staining was performed. For $\mathrm{KOH}$ smear, specimen was taken from the margins and base of the ulcer and was placed within a marked area on a glass slide. One drop of $10 \%$ $\mathrm{KOH}$ was put on it and a clean coverslip was added. The corneal scrapings were stained by the Gram and acidfast bacilli (AFB) stain methods, and also inoculated onto a variety of solid and liquid media that support the growth of bacteria, fungi, and acanthamoeba. These included thioglycolate broth, blood agar, MacConkey agar, and Sabouraud dextrose agar. Samples were inoculated into Sabouraud dextrose agar for fungal detection and incubated at room temperature or $30{ }^{\circ} \mathrm{C}$ for 21 days.

When a fungal infection is clinically suspected or when a fungus is identified, systemic and topical antifungal agent was administered immediately. The first-line antifungal used was topical amphotericin B given hourly. In cases where no response was seen within $72 \mathrm{~h}$, topical $5 \%$ natamycin (Natacin , Alcon, Fort Worth, TX, USA) was added to the above regimen. Systemic antifungal agents (fluconazole $50 \mathrm{mg}$ tid p.o. / intravenous amphotericin B) were administered. Topical $1 \%$ voriconazole was used in cases where there was no improvement in the lesion even after 2 weeks of continuous use of amphotericin B eyedrop and 5\% natamycin, or when 
anterior chamber fungal ball was formed. All patients were treated topically with 3rd or 4th generation fluoroquinolones and fortified topical antibiotics (2\% tobramycin, $5 \%$ ceftazidime) and systemic antibiotics before the microbiological results were obtained as empirical treatment. When topical steroids were in use at the initial presentation, they were gradually tapered. The treatment outcomes were assessed at the end of 3 months or at the completion of treatment. Treatment outcomes were evaluated by epithelial healing time (EHT), complication, surgical intervention, and final BCVA. Treatment failure was defined as the occurrence of complications or need for surgical treatment.

The data were analyzed using the Statistical Package for the Social Sciences 20.0 (IBM, Armonk, NY, USA). Chi-square test and Fisher's exact test were used for categorical data. Independent $t$-tests were used for comparison of mean values. Statistical significance was indicated by $p<0.05$ (two-tailed). The risk factors for treatment failure were analyzed using logistic regression analysis in the overall cohort. An independent variable with a $p<0.1$ from the univariate analysis was included in the multivariate analysis and a variable with a final $p<0.05$ was considered as a significant risk factor.

\section{Results}

\section{Baseline epidemiology, predisposing factors, and clinical characteristics}

Over a 17-year period, we identified 89 microbiologically proven fungal keratitis cases. Of these, six cases had accompanying necrotizing scleritis. These 6 cases were excluded, leaving 83 microbiologically proven cases of fungal keratitis being enrolled in this study. Of these, thirty cases $(36.1 \%)$ were in the PS group and 53 cases (63.9\%) were in the NPS group.

Table 1 compares the baseline epidemiology, predisposing factors, and clinical characteristics of the PS and NPS groups. For the overall cohort, the mean age was $63.0 \pm 14.3$ years and $57.8 \%$ were males. About half of patients were agricultural workers in both groups (PS: $46.7 \%$, NPS: $47.2 \%)$. There were no significant differences in the mean age, sex, and occupational distribution between the PS and NPS groups. The median time to symptom duration was 14 days in the PS group and 10 days in the NPS group, the difference being statistically not significant. Among the PS group, $36.7 \%$ of topical steroids were used in primary eye clinic and 63.3\% were used in our hospital.

Corneal trauma $(70.0,81.1 \%)$ was the most common predisposing factor in both groups. The ratios of previous OSD ( $43.3 \%$ vs. $22.6 \%, p=0.048)$ and previous ocular surgery $(33.3 \%$ vs. $18.9 \%, p=0.139)$ were higher in the PS group. Herpetic keratitis $(23.3,9.4 \%)$ was the most common previous OSD in both groups.
Table 1 Baseline epidemiology, predisposing factors and clinical characteristics of fungal keratitis according to prior topical steroid use

\begin{tabular}{|c|c|c|c|}
\hline Characteristics & $\begin{array}{l}\text { PS } \\
(n=30)\end{array}$ & $\begin{array}{l}\text { NPS } \\
(n=53)\end{array}$ & $p$-value \\
\hline \multicolumn{4}{|l|}{ Epidemiology } \\
\hline Male sex & $19(63.3)$ & $29(54.7)$ & 0.445 \\
\hline Age, years & $60.2 \pm 14.9$ & $64.6 \pm 13.9$ & 0.180 \\
\hline \multicolumn{4}{|l|}{ Occupation } \\
\hline Agriculture & $14(46.7)$ & $25(47.2)$ & \multirow[t]{2}{*}{0.965} \\
\hline Non-agriculture & $16(53.3)$ & $28(52.8)$ & \\
\hline $\begin{array}{l}\text { Symptom duration, } \\
\text { days }\end{array}$ & $19.7 \pm 15.4$ & $15.0 \pm 13.8$ & 0.154 \\
\hline Median (range) & $14(2-150)$ & $10(1-90)$ & $0.127^{\dagger}$ \\
\hline $\begin{array}{l}\text { Referral from primary } \\
\text { eye clinic }\end{array}$ & $11(36.7)$ & $4(7.5)$ & 0.001 \\
\hline \multicolumn{4}{|l|}{ Predisposing factors } \\
\hline Corneal trauma & $21(70.0)$ & $43(81.1)$ & 0.246 \\
\hline $\begin{array}{l}\text { Vegetable matter } \\
\text { or wood }\end{array}$ & $8(26.7)$ & $21(39.6)$ & 0.234 \\
\hline Soil or water & $9(30.0)$ & $16(30.2)$ & 0.986 \\
\hline Other trauma & $4(13.3)$ & $6(11.3)$ & $1.000^{*}$ \\
\hline Previous OSD & $13(43.3)$ & $12(22.6)$ & 0.048 \\
\hline Herpetic keratitis & $7(23.3)$ & $5(9.4)$ & $0.108^{*}$ \\
\hline Punctate keratopathy & $3(10.0)$ & $2(3.8)$ & $0.346^{*}$ \\
\hline Old corneal opacity & $2(6.7)$ & $3(5.7)$ & $1.000^{*}$ \\
\hline Other keratopathy ${ }^{a}$ & $1(3.3)$ & $2(3.8)$ & $1.000^{*}$ \\
\hline Contact lens wear & $1(3.3)$ & $4(7.5)$ & $0.649^{*}$ \\
\hline Previous ocular surgery & $10(33.3)$ & $10(18.9)$ & 0.139 \\
\hline Systemic disease & $12(40.0)$ & $21(39.6)$ & 0.973 \\
\hline Diabetes mellitus & $4(13.3)$ & $10(18.9)$ & 0.518 \\
\hline Hypertension & $7(23.3)$ & $12(22.6)$ & 0.943 \\
\hline \multicolumn{4}{|l|}{ Initial clinical characteristics } \\
\hline Central corneal lesion & $22(73.3)$ & $42(79.2)$ & 0.538 \\
\hline $\begin{array}{l}\text { Epithelial defect } \\
\text { size }\left(\mathrm{mm}^{2}\right)\end{array}$ & $12.7 \pm 12.4$ & $10.5 \pm 11.2$ & 0.404 \\
\hline$\geq 10 \mathrm{~mm}^{2}$ & $13(43.3)$ & $16(30.2)$ & 0.228 \\
\hline \multicolumn{4}{|l|}{ Depth of infiltration } \\
\hline Superficial (0-50\%) & $14(46.7)$ & $36(67.9)$ & \multirow[t]{2}{*}{0.057} \\
\hline Deep (50-100\%) & $16(53.3)$ & $17(32.1)$ & \\
\hline Hypopyon & $9(30.0)$ & $17(32.1)$ & 0.845 \\
\hline $\begin{array}{l}\text { Presenting BCVA } \\
\text { (logMAR) }\end{array}$ & $1.63 \pm 0.96$ & $1.47 \pm 1.14$ & 0.486 \\
\hline$<0.1$, Snellen & $20(66.7)$ & $27(51.9)$ & 0.194 \\
\hline
\end{tabular}

Values are presented as mean \pm standard deviation or number (\%) $B C V A$ best corrected visual acuity, NPS group of no prior topical steroid use, OSD ocular surface disease, $P S$ group of prior topical steroid use "The $p$-value was calculated using Fisher's exact test ${ }^{+}$The $p$-value was calculated using Kruskal-Wallis test anclude neurotrophic keratopathy (PS), bullous keratopathy (NPS), and exposure keratopathy (NPS) 
Among the initial clinical characteristics, central corneal lesions were more common than peripheral ones in both groups. There were no significant differences in the location of corneal lesions and hypopyon between the two groups. The cases with epithelial defect size $\geq 10$ $\mathrm{mm}^{2}(p=0.228)$ and presenting BCVA $<0.1 \quad(p=0.194)$ were slightly higher in the PS group, but the differences were not statistically significant. There was a higher proportion of cases with deep infiltration in the PS group compared to the NPS group ( $53.3 \%$ vs. $32.1 \%, p=0.057)$.

\section{Microbiological test results}

Table 2 shows the microbiological test results including identified fungal isolates and $\mathrm{KOH}$ smear result. Thirty fungal isolates out of 30 eyes were identified in the overall group. Of these, sixteen fungal isolates in the PS group and 14 in the NPS group were identified. The most commonly identified fungal organisms were the Candida species (6 cases, respectively), followed by Fusarium species ( 3 cases, 5 cases), and Aspergillus species (4 cases, 0 case). There was no statistically significant difference between the PS group and the NPS in the distribution of Candida $(p=0.765)$ and Fusarium species $(p=0.417)$, while the Aspergillus species were found only in the PS group ( $p=0.103)$. Twenty cases (66.7\%) of $\mathrm{KOH}$ smear positive in the PS group and 46 cases (86.8\%) in the NPS group were identified. Six cases (20\%) of both culture and $\mathrm{KOH}$ smear positive in the PS group and 7 cases $(13.2 \%)$ in the NPS group were identified $(p=0.532)$.

\section{Treatment outcomes}

Of the overall patient population, sixty-three cases $(75.9 \%)$ received topical antifungal monotherapy, while 20 cases
(24.1\%) received a combined antifungal treatment. Combined topical antifungal treatment $(33.3 \%$ vs. $18.9 \%, p=$ $0.139)$ and voriconazole/natamycin combination (10\% vs. $0 \%, p=0.044$ ) were more common in the PS group than in the NPS. For systemic antifungal agents, fluconazole was the most commonly used in both groups (53.3, $67.9 \%)$, followed by amphotericin B $(26.7,32.1 \%)$. The use of systemic voriconazole was significantly higher in the PS group $(23.3 \%$ vs. $1.9 \%, p=0.003)$.

The median EHT was 27 days in the PS group and 23 days in the NPS group. Sixty percent of the PS group had a final BCVA of $<0.1$ compared to $44.2 \%$ in the NPS group (Table 3). As a complication, corneal perforation was the most common (8 cases, 7 cases) in both groups, followed by endophthalmitis ( 2 cases, 1 case). The proportion of corneal perforation was slightly higher in the PS group compared to the NPS group $(p=0.126)$.

Overall, twenty-four cases (28.9\%) required surgical intervention, the proportion being higher in the PS group ( $43.3 \%$ vs. $20.8 \%, p=0.029)$. In the PS group, amniotic membrane transplantation was performed in 9 cases, and 6 cases had conjunctival flap. In the NPS group, evisceration/enucleation was performed in 7 cases. The proportion of evisceration/enucleation (13\%, respectively) was similar between the two groups. The proportion of treatment failure was significantly higher in the PS group (46.7\% vs. $22.6 \%, p=0.023)$ (Table 3$)$.

\section{Risk factors for treatment failure}

In a multivariate logistic regression analysis, hypopyon (odds ratio [OR] 6.01, 95\% confidence interval [CI] 1.70-21.23, $p=0.005$ ) and deep infiltration (OR 4.38,

Table 2 Microbiological test results ${ }^{\mathrm{a}}$ according to prior topical steroid use

\begin{tabular}{|c|c|c|c|}
\hline & $\begin{array}{l}\text { PS } \\
(n=30)\end{array}$ & $\begin{array}{l}\text { NPS } \\
(n=53)\end{array}$ & $p$-value \\
\hline Identified fungal isolates ${ }^{\mathrm{b}}$ & $16(53.3)$ & $14(26.4)$ & 0.014 \\
\hline Candida species $^{\#}$ & $6(37.5)$ & $6(42.9)$ & 0.765 \\
\hline Fusarium species ${ }^{\#}$ & $3(18.8)$ & $5(35.7)$ & $0.417^{\S}$ \\
\hline Aspergillus species ${ }^{\#}$ & $4(25.0)$ & $0(0.0)$ & $0.103^{\S}$ \\
\hline Syncephalastrum species" & $0(0.0)$ & $1(7.1)$ & $0.467^{\S}$ \\
\hline Alternaria species" & $1(6.2)$ & $0(0.0)$ & $1.000^{\S}$ \\
\hline Cryptococcus species $^{\#}$ & $1(6.2)$ & $0(0.0)$ & $1.000^{\S}$ \\
\hline Acremonium species ${ }^{\#}$ & $1(6.2)$ & $0(0.0)$ & $1.000^{\S}$ \\
\hline Unknown species" & $0(0.0)$ & $2(3.8)$ & $0.209^{\S}$ \\
\hline $\mathrm{KOH}$ smear positive & $20(66.7)$ & $46(86.8)$ & 0.029 \\
\hline Identified fungal isolates and $\mathrm{KOH}$ smear positive & $6(20.0)$ & $7(13.2)$ & $0.532^{\S}$ \\
\hline
\end{tabular}

Values are presented as number (\%)

$K O H$ potassium hydroxide, NPS group of no prior topical steroid use, $P C R$ polymerase chain reaction, $P S$ group of prior topical steroid use

"Percentage and $p$-value of each species were calculated based on the identified fungal isolates

${ }^{5}$ The $p$-value was calculated using Fisher's exact test

${ }^{a}$ Defined as positive result if at least one of the following is included: (a) positive fungal culture from a corneal specimen, (b) positive identification of fungal elements on a $10 \% \mathrm{KOH}$ smear, (c) positive identification of fungal elements on multiplex PCR, or (d) histopathology showing presence of fungal elements

bIdentified by culture, multiplex PCR, and biopsy 
Table 3 Treatment outcome of fungal keratitis according to prior topical steroid use

\begin{tabular}{|c|c|c|c|}
\hline Characteristics & $\begin{array}{l}\text { PS } \\
(n=30)\end{array}$ & $\begin{array}{l}\text { NPS } \\
(n=53)\end{array}$ & $p$-value \\
\hline \multicolumn{4}{|l|}{ Medical treatment: topical } \\
\hline $\begin{array}{l}\text { Antifungal agent } \\
\text { monotherapy }\end{array}$ & $20(66.7)$ & $43(81.1)$ & 0.139 \\
\hline Amphotericin B & $8(26.7)$ & $19(35.8)$ & 0.391 \\
\hline Natamycin & $12(40.0)$ & $24(45.3)$ & 0.641 \\
\hline $\begin{array}{l}\text { Combined antifungal } \\
\text { agents }\end{array}$ & $10(33.3)$ & $10(18.9)$ & 0.139 \\
\hline $\begin{array}{l}\text { Amphotericin B/ } \\
\text { natamycin }\end{array}$ & $7(23.3)$ & $10(18.9)$ & 0.628 \\
\hline $\begin{array}{l}\text { Voriconazole/ } \\
\text { natamycin }\end{array}$ & $3(10.0)$ & $0(0.0)$ & $0.044^{*}$ \\
\hline \multicolumn{4}{|l|}{$\begin{array}{l}\text { Medical treatment: } \\
\text { systemic }^{\mathrm{a}}\end{array}$} \\
\hline Terbinafine & $5(16.7)$ & $4(7.5)$ & $0.273^{*}$ \\
\hline Itraconazole & $1(3.3)$ & $4(7.5)$ & $0.649^{*}$ \\
\hline Fluconazole & $16(53.3)$ & $36(67.9)$ & 0.187 \\
\hline Amphotericin B & $8(26.7)$ & $17(32.1)$ & 0.606 \\
\hline Voriconazole & $7(23.3)$ & $1(1.9)$ & $0.003^{*}$ \\
\hline \multicolumn{4}{|l|}{ Treatment outcome } \\
\hline $\begin{array}{l}\text { Epithelial healing } \\
\text { time, days }{ }^{b}\end{array}$ & $44.6 \pm 50.5$ & $29.6 \pm 27.9$ & 0.165 \\
\hline Median (range) & $27(4-190)$ & $23(3-150)$ & $0.248^{+}$ \\
\hline Final BCVA ${ }^{c}(\log M A R)$ & $1.36 \pm 1.20$ & $0.92 \pm 1.08$ & 0.133 \\
\hline$<0.1$, Snellen & $18(60.0)$ & $23(44.2)$ & 0.169 \\
\hline \multicolumn{4}{|l|}{ Complications } \\
\hline Corneal perforation & $8(26.7)$ & $7(13.2)$ & 0.126 \\
\hline Endophthalmitis & $2(6.7)$ & $1(1.9)$ & $0.295^{*}$ \\
\hline Surgical intervention & $13(43.3)$ & $11(20.8)$ & 0.029 \\
\hline AMT & $9(30.0)$ & $4(7.5)$ & $0.011^{*}$ \\
\hline Evisceration/enucleation & $4(13.3)$ & $7(13.2)$ & $1.000^{*}$ \\
\hline Conjunctival flap & $6(20.0)$ & $4(7.5)$ & $0.157^{*}$ \\
\hline Penetrating keratoplasty & $0(0.0)$ & $1(1.9)$ & $1.000^{*}$ \\
\hline $\begin{array}{l}\text { Time to evisceration/enucleation } \\
<1 \text { month }^{d}\end{array}$ & $2 / 4(50.0)$ & $5 / 7(71.4)$ & 0.576 \\
\hline $\begin{array}{l}\text { Duration of hospitalization, } \\
\text { days }^{\text {e }}\end{array}$ & $15.6 \pm 6.3$ & $13.0 \pm 6.0$ & 0.070 \\
\hline Treatment failure $^{f}$ & $14(46.7)$ & $12(22.6)$ & 0.023 \\
\hline
\end{tabular}

Values are presented as mean \pm standard deviation or number (\%) $A M T$ amniotic membrane transplantation, BCVA best corrected visual acuity, logMAR logarithm of the minimal angle of resolution, NPS group of no prior topical steroid use, PS group of prior topical steroid use

"The $p$-value was calculated using Fisher's exact test

${ }^{\dagger}$ The $p$-value was calculated using Kruskal-Wallis test

a Percent do not add to $100 \%$ because some cases had combined systemic medications

${ }^{\text {b}}$ Total $n=71$ : cases with persistent epithelial defect were excluded. (3 cases in PS, 9 cases in NPS)

${ }^{\top}$ The final BCVA was assessed at the end of 3 months or at the completion of treatment

${ }^{d}$ Percentages and statistical values were calculated within the group of underwent evisceration/enucleation

${ }^{\mathrm{e}}$ Total $n=77$ : cases of outpatients were excluded ( 2 cases in PS, 4 cases in NPS)

fDefined as the occurrence of complication or surgical intervention
95\% CI 1.37-14.08, $p=0.013)$ were identified as significant risk factors for treatment failure. Prior topical steroid use (OR 2.79, 95\% CI 0.85-9.18, $p=0.091$ ) and previous OSD (OR 2.82, 95\% CI 0.84-9.49, $p=0.093$ ) were not significant in multivariate analysis (Table 4).

\section{Discussion}

In this study, $36.1 \%$ of patients were exposed to topical steroids prior to their diagnosis of fungal keratitis. A history of previous OSD and ocular surgery was more frequently observed in the PS group. These findings were likely due to the past use of steroids prescribed for treatment of the patients' underlying conditions. A previous Korean study reported that in $14.1 \%$ of fungal keratitis cases, patients had been prescribed topical steroids prior to their diagnosis [10]. Studies in other countries have reported a range from $13 \%$ to $44 \%$ [11-13].

The types and distribution of the microbiological profile of fungal keratitis vary according to geography, climate, and the socioeconomic characteristics of the patients involved. In this study, the most commonly identified organism in both groups was Candida species (20\% in PS and $11.3 \%$ in NPS) followed by Fusarium species. Our findings in relation to Candida species are similar to the results of studies conducted across the globe, i.e., London (60.6\%) [14], Paris (58\%) [15], Denmark (52\%) [11], and Pennsylvania (45.8\%) [16]. In contrast, studies in north China (73.3\%) [17], Florida (41\%) [18], Mexico City (37.2\%) [19], south India (37.2\%) [20], central China (30.6\%) [21], and Korea (29\%) [10] reported that Fusarium was the most commonly identified organism. Aspergillus was the most commonly identified organism in reports from north India (41\%) and Saudi Arabia (27.2\%) [22, 23]. Our study determined that Aspergillus was found only in the PS group. This result can be supported by the study of Tony et al. who had reported that corticosteroids promote the growth of Aspergillus [24].

The authors anticipated that the PS group would have more severe initial clinical characteristics than the NPS group. However, our study found no significant differences in initial clinical characteristics between the two groups except in terms of depth of infiltration. We speculate that this finding may be related to the inflammationmasking effect of previous topical steroids used in early stage of keratitis. This finding may also make clinical suspicion and early diagnosis of fungal keratitis difficult. At initial presentation, deep infiltration of the infection was higher in the PS group. In a study by Panda et al., it was reported that hyphae are located more vertically in a group that used steroids [25]. Fungi are characterized by deep penetration into the corneal stroma, and vertically located hyphae are more involved in penetration and are more virulent [25]. A study by Lixin et al., found that the 
Table 4 Risk factors for treatment failure ${ }^{a}$ in fungal keratitis using univariate and multivariate logistic regression analysis

\begin{tabular}{|c|c|c|c|c|c|c|}
\hline \multirow[t]{2}{*}{ Variables } & \multicolumn{3}{|c|}{ Univariate analysis } & \multicolumn{3}{|c|}{ Multivariate analysis $^{\dagger}$} \\
\hline & $\mathrm{OR}$ & $95 \% \mathrm{Cl}$ & $p$-value & $\mathrm{OR}$ & $95 \% \mathrm{Cl}$ & $p$-value \\
\hline Female sex & 1.27 & $0.50-3.23$ & 0.620 & & & \\
\hline Age $\geq 60$ years & 1.80 & $0.62-5.21$ & 0.277 & & & \\
\hline Agricultural occupation & 0.48 & $0.18-1.25$ & 0.130 & & & \\
\hline Corneal trauma & 0.22 & $0.08-0.66$ & 0.006 & - & - & - \\
\hline Prior topical steroid use & 2.99 & $1.14-7.84$ & 0.026 & 2.79 & $0.85-9.18$ & 0.091 \\
\hline Previous OSD & 2.90 & $1.08-7.80$ & 0.035 & 2.82 & $0.84-9.49$ & 0.093 \\
\hline Previous herpetic keratitis & 2.55 & $0.74-8.85$ & 0.140 & & & \\
\hline Previous ocular surgery & 1.25 & $0.43-3.62$ & 0.685 & & & \\
\hline Diabetes mellitus & 2.63 & $0.81-8.51$ & 0.106 & & & \\
\hline Symptom duration $\geq 10$ days & 1.34 & $0.52-3.46$ & 0.543 & & & \\
\hline Central corneal lesion & 1.02 & $0.34-3.06$ & 0.978 & & & \\
\hline Epithelial defect size $\geq 10 \mathrm{~mm}^{2}$ & 2.56 & $0.98-6.70$ & 0.055 & - & - & - \\
\hline Deep infiltration & 8.34 & $2.90-23.96$ & $<0.001$ & 4.38 & $1.37-14.08$ & 0.013 \\
\hline Hypopyon & 5.70 & $2.06-15.80$ & 0.001 & 6.01 & $1.70-21.23$ & 0.005 \\
\hline Presenting BCVA $<0.1$, Snellen & 4.85 & $1.60-14.67$ & 0.005 & - & - & - \\
\hline
\end{tabular}

$B C V A$ best corrected visual acuity, $C l$ confidence interval, OR odds ratio, OSD ocular surface disease;

${ }^{a}$ Treatment failure was defined as the occurrence of complication or surgical intervention

${ }^{\dagger}$ Multivariate logistic regression analysis was performed using the backward-conditional method for the factors with a $p$-value $<0.1$ in univariate logistic regression analysis

vertically growing hyphae had a higher recurrence rate after lamellar keratoplasty than horizontally growing hyphae [26]. Therefore, it is important to evaluate the detailed characteristics of the lesion and to collect a comprehensive patient history at the initial visit.

In this study, only microbiologically proven fungal keratitis was included, and microbiological evidences of fungus were made through potassium hydroxide smear, culture, PCR, or biopsy. The percentage of identified fungal isolates was higher in the PS group than in the NPS group. One potential interpretation of this result is that steroid use can promote fungal proliferation, thereby enhancing its identification. However, the relationship between the use of prior topical steroids and the positive rate of culture has rarely been reported. Further studies are needed to investigate the origin of relationship. Furthermore, this study does not have a prospective design, and it does not include the cases of negative microbiological tests. Therefore, there is a limit to evaluation and interpretation.

There was no significant difference in the type and proportion of antifungal agents used between the two groups, but topical and systemic voriconazole use was significantly higher in the PS group. In the medical center where the authors practice, the use of topical and systemic voriconazole when there is no response to conventional antifungal therapy. The significantly higher use of topical and systemic voriconazole in the PS group indicates that the treatment response was worse than that anticipated in this group.
The PS group had significantly higher surgical intervention and treatment failure than the NPS group. This is consistent with the results of other studies that have suggested that the prior use of topical steroids in fungal keratitis may contribute to worse outcomes [27, 28]. These results highlight the side effects of prior topical steroid use in the cases of fungal keratitis. Evisceration/ enucleation was performed in $13.3 \%$ of the overall patients. These results were similar to the proportion of eviceration/enucleation (10.6\%) reported in a multicenter study in Korea [10]. The authors expected that there would be higher incidence of evisceration/enucleation in the PS, just as more surgical treatments were needed in the PS group. However, in this study, no significant difference was observed in the proportion of evisceration/ enucleation between the PS and the NPS groups (13.3\%, 13.2\%). Therefore, we performed an additional logistic regression analysis to determine the risk factors for evisceration/enucleation. As a result, hypopyon (PS: 30\%, NPS: 32\%) was the only significant risk factor for evisceration/enucleation (OR 4.88, 95\% CI 1.28-18.56, $p=$ 0.020). Thus, the risk factors for evisceration/enucleation was associated with initial clinical severity of the overall cohort, and further study will be needed.

In this study, significant risk factors for treatment failure were hypopyon and deep infiltration. Prior topical steroid use and previous OSD were significant in univariate logistic regression analysis but their effects were attenuated in multivariate analysis. Hypopyon can be 
regarded as a marker of inflammation. A study of Lalitha et al. reported that the presence of hypopyon was a significant predictor of treatment failure [29]. And deep stromal infiltration was a significant risk factor for treatment failure. The depth of infiltration may reflect the progression of the lesion, and the poor corneal penetration of antifungal agents may be related to the difficulty of treatment in the case of deep infiltration [3, 4]. Therefore, it is important to evaluate these features at the initial visit because fungal keratitis can penetrate deeply into the stroma in the early stage of infection. Other studies have reported various risk factors for treatment failure in fungal keratitis such as large epithelial defect size and prior topical steroid use [30, 31].

The reported role of steroids in fungal keratitis includes suppression of inflammation and subsequent growth promotion of the fungal genus. Moreover, vertically oriented hyphae are more commonly observed in the eyes of patients who used steroids [25]. Steroid use has been associated with a decreased response to antifungal agents, and steroid treatment itself is a known risk factor for fungal infection $[8,28,32]$. Steroid worsen infections due to severe inflammatory side effects and they also affect the delay of epithelial regeneration [3336]. Therefore, it should be emphasized that early steroid use is contraindicated when an infection is suspected. Clinicians should be cautious when prescribing steroids for suspected cases of infectious keratitis.

This study has some limitations. First, this study was confined to South Korea, which is temperate climate. And the cases included were from one tertiary hospital. Therefore, the results of this study cannot be generalized. Second, owing to the study's retrospective design, the authors could not accurately identify the potency and dose of the topical steroids prescribed for patients who were referred from their primary eye clinics. Third, only the patients with microbiological evidence of fungal keratitis were enrolled in this study while cases without such evidence were excluded, even if fungal keratitis was highly suspected. Despite such limitations, this study has an important clinical significance. This investigation highlighting the risk and side effects associated with prior topical steroid use in practical clinical circumstances. This study is a clinical analysis of fungal keratitis in South Korea. Clinician may use these findings as a beneficial reference for various regional differences in fungal keratitis.

\section{Conclusions}

In this study, $36.1 \%$ of the patients used topical steroids prior to their diagnosis of microbiologically proven fungal keratitis. Previous OSD and deep infiltration were more common in the PS group than the NPS group. The use of systemic or topical voriconazole, surgical intervention and treatment failure were more common in the PS group. Hypopyon and deep infiltration of the infection were significant risk factors for treatment failure. Considering the risk for complications, the results of this study suggest that topical steroids should be administered with caution. Therefore, it is important to use topical steroids judiciously in ocular surface diseases such as keratitis, and to monitor patients frequently during steroid treatment.

\section{Abbreviations \\ BCVA: Best-corrected visual acuity; Cl: Confidence interval; EHT: Epithelial healing time; $\mathrm{KOH}$ : potassium hydroxide; NPS: No prior topical steroid use group; OR: Odds ratio; OSD: Ocular surface disease; PCR: Polymerase chain reaction; PS: Prior topical steroid use group}

\section{Acknowledgements}

Not applicable.

\section{Authors' contributions}

CHC: literature research, drafting, language editing, and critical revision. SBL: patient interaction, patient diagnosis, language editing, and critical revision. Both authors read and approved the final manuscript.

Funding

This work was supported by the 2018 Yeungnam University Research Grant.

\section{Availability of data and materials}

The datasets used and/or analyzed during the current study available from the corresponding author on reasonable request.

\section{Ethics approval and consent to participate}

This study was approved by the Institutional Review Board of the Yeungnam University Hospital, South Korea (file no. YUMC 2018-11-015), and complied with the principles outlined in the Declaration of Helsinki. Institutional Review Board of our institution allowed us "waiver of informed consent" because it is determined that obtaining consent from a human subject of research is impracticable in the course of research and the risk to a human subject of research is very low even if the project is exempted from consent, as per the Bioethics and Safety Act of the Republic of Korea (Chapter 3, Article 16, Paragraph 3, Act No. 14839. Enforcement Date 26. July 2017.).

\section{Consent for publication}

Not applicable.

\section{Competing interests}

The authors declare that they have no competing interests.

Received: 24 January 2019 Accepted: 10 September 2019

Published online: 16 October 2019

\section{References}

1. Chen WL, Wu CY, Hu FR, Wang IJ. Therapeutic penetrating keratoplasty for microbial keratitis in Taiwan from 1987 to 2001. Am J Ophthalmol. 2004; 137(4):736-43

2. Wong TY, Ng TP, Fong KS, Tan DT. Risk factors and clinical outcomes between fungal and bacterial keratitis: a comparative study. CLAO J. 1997; 23(4):275-81.

3. O'Day DM, Head WS, Robinson RD, Clanton JA. Corneal penetration of topical amphotericin B and natamycin. Curr Eye Res. 1986:5(11):877-82.

4. Thomas PA. Fungal infections of the cornea. Eye (Lond). 2003;17(8):852-62.

5. Srinivasan M. Fungal keratitis. Curr Opin Ophthalmol. 2004;15(4):321-7.

6. Jurkunas U, Behlau I, Colby K. Fungal keratitis: changing pathogens and risk factors. Cornea. 2009;28(6):638-43.

7. Thygeson P, Hogan MJ, Kimura SJ. Cortisone and hydrocortisone in ocular infections. Trans Am Acad Ophthalmol Otolaryngol. 1953;57(1):64-85.

8. Lionakis MS, Kontoyiannis DP. Glucocorticoids and invasive fungal infections. Lancet. 2003;362(9398):1828-38. 
9. Mukerji N, Vajpayee RB, Sharma N. Technique of area measurement of epithelial defects. Cornea. 2003;22(6):549-51.

10. Hahn YH, Lee DJ, Kim MS, Choi SH, Kim JD. Epidemiology of fungal keratitis in Korea: a multi-center study. J Korean Ophthalmol Soc. 2000; 41(7):1499-508.

11. Nielsen SE, Nielsen E, Julian HO, Lindegaard J, Hojgaard K, Ivarsen A Hjortdal J, Heegaard S. Incidence and clinical characteristics of fungal keratitis in a Danish population from 2000 to 2013. Acta Ophthalmol. 2015; 93(1):54-8.

12. Ong HS, Fung SSM, Macleod D, Dart JKG, Tuft SJ, Burton MJ. Altered patterns of fungal keratitis at a London ophthalmic referral hospital: an eight-year retrospective observational study. Am J Ophthalmol. 2016; 168:227-36

13. Keay $\sqcup$, Gower EW, lovieno A, Oechsler RA, Alfonso EC, Matoba A, Colby K, Tuli SS, Hammersmith K, Cavanagh D, et al. Clinical and microbiological characteristics of fungal keratitis in the United States, 2001-2007: a multicenter study. Ophthalmology. 2011;118(5):920-6.

14. Galarreta DJ, Tuft SJ, Ramsay A, Dart JK. Fungal keratitis in London: microbiological and clinical evaluation. Cornea. 2007;26(9):1082-6.

15. Rondeau N, Bourcier T, Chaumeil C, Borderie V, Touzeau O, Scat Y, Thomas F, Baudouin C, Nordmann JP, Laroche L. Fungal keratitis at the Centre Hospitalier national d'Ophtalmologie des Quinze-Vingts: retrospective study of 19 cases. J Fr Ophtalmol. 2002;25(9):890-6.

16. Tanure MA, Cohen EJ, Sudesh S, Rapuano CJ, Laibson PR. Spectrum of fungal keratitis at wills eye hospital, Philadelphia, Pennsylvania. Cornea. 2000;19(3):307-12.

17. Xie L, Zhong W, Shi W, Sun S. Spectrum of fungal keratitis in North China. Ophthalmology. 2006;113(11):1943-8.

18. Iyer SA, Tuli SS, Wagoner RC. Fungal keratitis: emerging trends and treatment outcomes. Eye Contact Lens. 2006;32(6):267-71.

19. Vanzzini Zago V, Manzano-Gayosso P, Hernandez-Hernandez F, MendezTovar LJ, Gomez-Leal A, Lopez Martinez R. Mycotic keratitis in an eye care hospital in Mexico City. Rev Iberoam Micol. 2010;27(2):57-61.

20. Gopinathan U, Garg P, Fernandes M, Sharma S, Athmanathan S, Rao GN The epidemiological features and laboratory results of fungal keratitis: a 10year review at a referral eye care center in South India. Cornea. 2002;21(6): 555-9.

21. Wang $L$, Sun $S$, Jing $Y$, , Han $L$, Zhang $H$, Yue J. Spectrum of fungal keratitis in Central China. Clin Exp Ophthalmol. 2009;37(8):763-71.

22. Chowdhary A, Singh K. Spectrum of fungal keratitis in North India. Cornea. 2005;24(1):8-15.

23. Jastaneiah SS, Al-Rajhi AA, Abbott D. Ocular mycosis at a referral center in Saudi Arabia: a 20-year study. Saudi J Ophthalmol. 2011;25(3):231-8.

24. Ng TT, Robson GD, Denning DW. Hydrocortisone-enhanced growth of Aspergillus spp.: implications for pathogenesis. Microbiology. 1994;140(Pt 9): 2475-9.

25. Panda A, Mohan M, Mukherjee G. Mycotic keratitis in Indian patients (a histopathological study of corneal buttons). Indian J Ophthalmol. 1984;32(5): 311-5.

26. Xie L, Zhai H, Shi W, Zhao J, Sun S, Zang X. Hyphal growth patterns and recurrence of fungal keratitis after lamellar keratoplasty. Ophthalmology. 2008;115(6):983-7

27. Wong TY, Au Eong KG, Chan WK, Tseng PS. Fusarium keratitis following the use of topical antibiotic-corticosteroid therapy in traumatised eyes. Ann Acad Med Singap. 1996;25(6):862-5.

28. Stern GA, Buttross M. Use of corticosteroids in combination with antimicrobial drugs in the treatment of infectious corneal disease. Ophthalmology. 1991;98(6):847-53.

29. Lalitha P, Prajna NV, Kabra A, Mahadevan K, Srinivasan M. Risk factors for treatment outcome in fungal keratitis. Ophthalmology. 2006;113(4):526-30.

30. Lee $\mathrm{DH}$, Ko HC, Lee JE. Analysis of clinical manifestations and risk factors for treatment failure in fungal keratitis. Korean J Med Mycol. 2015;20(4):83-92.

31. Prajna NV, Krishnan T, Mascarenhas J, Srinivasan M, Oldenburg CE, ToutainKidd CM, Sy A, McLeod SD, Zegans ME, Acharya NR, et al. Predictors of outcome in fungal keratitis. Eye (Lond). 2012;26(9):1226-31.

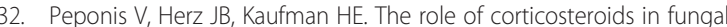
keratitis: a different view. Br J Ophthalmol. 2004;88(9):1227.

33. Chung $\mathrm{JH}$, Kang YG, Kim HJ. Effect of $0.1 \%$ dexamethasone on epithelia healing in experimental corneal alkali wounds: morphological changes during the repair process. Graefes Arch Clin Exp Ophthalmol. 1998;236(7): 537-45.
34. Tomas-Barberan S, Fagerholm P. Influence of topical treatment on epithelial wound healing and pain in the early postoperative period following photorefractive keratectomy. Acta Ophthalmol Scand. 1999;77(2):135-8.

35. Gritz DC, Kwitko S, Trousdale MD, Gonzalez VH, McDonnell PJ. Recurrence of microbial keratitis concomitant with antiinflammatory treatment in an animal model. Cornea. 1992;11(5):404-8.

36. Gritz DC, Lee TY, Kwitko S, McDonnell PJ. Topical anti-inflammatory agents in an animal model of microbial keratitis. Arch Ophthalmol. 1990;108(7):1001-5.

\section{Publisher's Note}

Springer Nature remains neutral with regard to jurisdictional claims in published maps and institutional affiliations.
Ready to submit your research? Choose BMC and benefit from:

- fast, convenient online submission

- thorough peer review by experienced researchers in your field

- rapid publication on acceptance

- support for research data, including large and complex data types

- gold Open Access which fosters wider collaboration and increased citations

- maximum visibility for your research: over $100 \mathrm{M}$ website views per year

At BMC, research is always in progress.

Learn more biomedcentral.com/submissions 